\title{
Penile Kaposi Sarcoma
}

National Cancer Institute

\section{Source}

National Cancer Institute. Penile Kaposi Sarcoma. NCI Thesaurus. Code C6377.

A Kaposi sarcoma arising from the penis. 